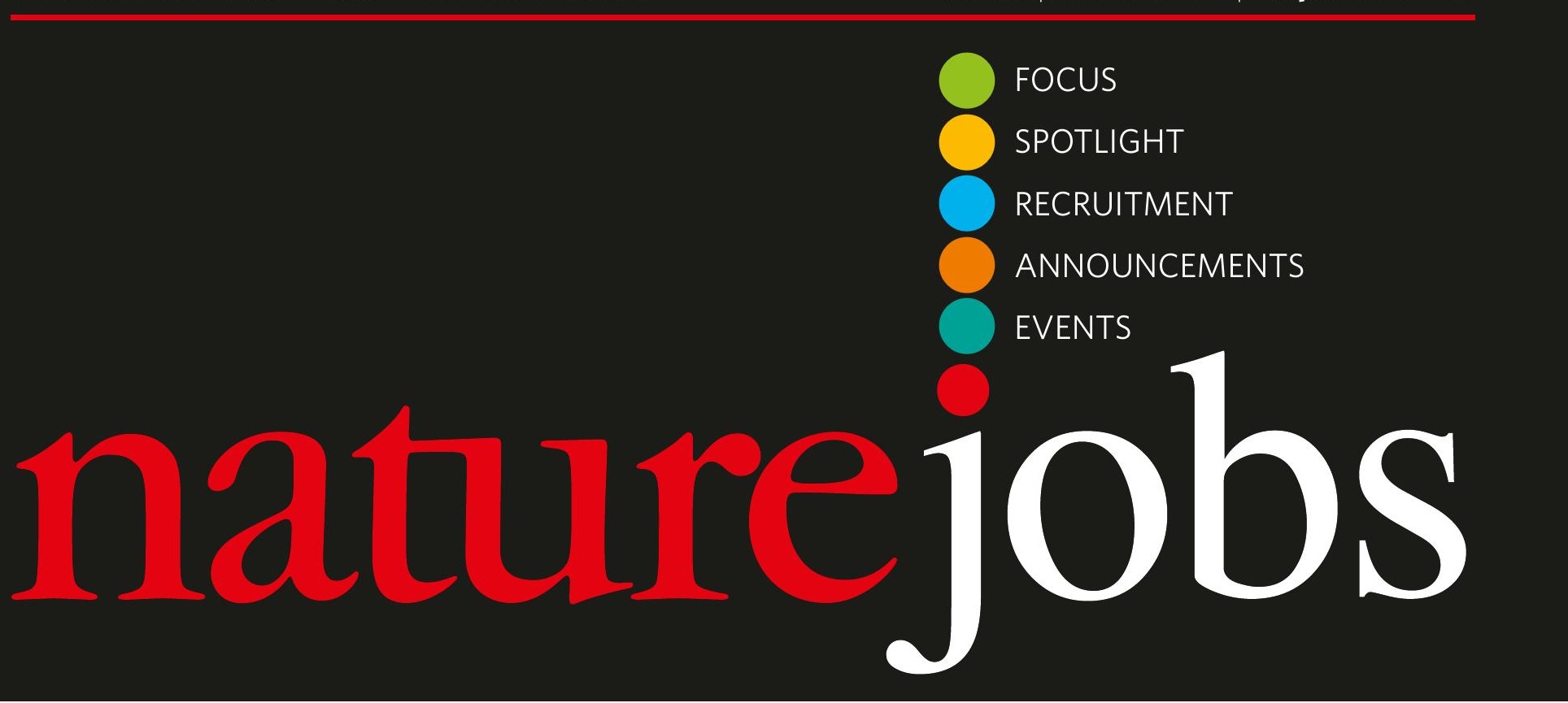

\title{
A boost for the Big Apple
}

New York is a great place to get a scientific education. But for young researcher looking to switch from academia to local industry, the city has always lagged behind the scientific hubs in California and Massachusetts.

It is true that New York has one of the highest concentrations of world-class universities and hospitals - New York University, Columbia University, Rockefeller University and the Memorial Sloan-Kettering Cancer Center, for example, are all within a short walk or subway ride from each other. But other than a few small incubators, biotechnology companies have largely been absent especially from Manhattan, where most of the academic research institutions are located.

That may now change, thanks to two developments announced last month that together total more than $\$ 800$ million in investment. One will boost the biotech sector, the other, the basic research that spurs it. The first is a $\$ 700$ million research complex called the East River Science Park, which will consist of 78,000 square metres of lab and office space. The project, to be built in two phases, will begin construction in 2006; the first 46,000 square metres will be finished in 2008. It is being funded by the city, and developed by California scientific building specialists Alexandria Real Estate Equities. The company will pay the city $\$ 3$ million a year rent, and act as a landlord for the site's tenants.

Meanwhile, New York University is set to receive a donation of some $\$ 105$ million from Jan Vilcek, a professor there who made his fortune by co-discovering the blockbuster drug Remicade, which is used to treat Crohn's disease and arthritis. The money will be used to fund basic microbiology research at the university - the kind that led Vilcek to his drug.

Together, the two developments should bring more entrepreneurially minded researchers to the city - and, if Vilcek's generosity is any example, draw in even more funding to fuel the next generation of scientists.

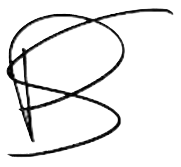

\section{Paul Smaglik, Naturejobs editor}

CONTACTS

Publisher: Ben Crowe

Editor: Paul Smaglik

Marketing Manager: David Bowen

US Head Office, New York

345 Park Avenue South, 10th Floor,

New York, NY 10010-1707

Tel: +1 8009897718

Fax: +18009897103

e-mail: naturejobs@natureny.com

US Sales Manager/Corporations: Peter Bless

Classified Sales Representatives

Tel: +1800989 7718
New York/Pennsylvania/

Latin America: Kelly Roman

Midwest USA/Maryland/

NIH: Wade Tucker

East USA/Canada:

Janine Taormina

San Francisco Office

Classified Sales Representative:

Michaela Bjorkman

West USA/West Corp. Canada

225 Bush Street, Suite 1453

San Francisco, CA 94104

Tel: +1415 7813803

Fax: +1 4157813805

e-mail:m.bjorkman@naturesf.com
European Head Office, London

The Macmillan Building,

4 Crinan Street,

London N19XW, UK

Tel: +44 (0) 2078434961

Fax: +44 (0) 2078434996

e-mail:naturejobs@nature.com

Naturejobs Sales Director: Nevin Bayoumi (4978) European Sales Manager: Andy Douglas (4975)

Advertising Production Manager: Billie Franklin To send materials use London address above. Tel: +44 (0) 2078434814

Fax: +44 (0) 2078434996

e-mail: naturejobs@nature.com
Naturejobs web development: Tom Hancock Naturejobs online production: Niamh Shields

European Satellite Office

Patrick Phelan

e-mail:p.phelan@nature.com

Japan Head Office, Tokyo

Chiyoda Building,

2-37 Ichigayatamachi,

Shinjuku-ku,

Tokyo $162-0843$

Tel: +81332678751

Fax: +81332678746

Asia-Pacific Sales Director: Rinoko Asami

e-mail: r.asami@naturejpn.com 